\title{
Global Logistics Intelligent Decision System of Medical Equipment Manufacturing
}

\author{
Sk Ahad $\mathrm{Ali}^{1}$, Hamid Seifoddini ${ }^{2}$ and Jay Lee ${ }^{3}$ \\ 'University of Puerto Rico-Mayaguez, Puerto Rico, USA \\ ${ }^{2}$ University of Wisconsin-Milwaukee, Wisconsin, USA \\ ${ }^{3}$ University of Cincinnati, Cincinnati, USA
}

\begin{abstract}
Global logistics aim to optimize and control the material/product flow and the information flow so that materials/products can be moved at a desired pace, in a proper fashion and at the right volume. The production processes in the medical equipment manufacturing industries are highly automated and dynamic and the orders are customized. This study presents an intelligent global logistics system for scheduling and planning of medical equipment production systems to minimize logistics cost. The optimization technique for production scheduling in the supply chains of medical equipments shows how an intelligent logistics system can effectively solve real-world problem. This research develops an intelligent decision system for global logistics of medial equipment manufacturing system. The proposed system is verified with real-world application. Medical equipment manufacturers can get benefit of the proposed optimization system.
\end{abstract}

Keywords: Global logistics, Supply chain, Medical equipments

\section{INTRODUCTION}

Nowadays companies want to establish relationships with external partners to identify their demands and effective responses. Supply chain management is the process of strategically managing the market oriented, manufacturing based and logistics supported movement and storage of materials, parts and finished inventory from suppliers through the company and onto customers. Figure 1 shows a typical supply chain how suppliers, manufacturers and customers are integrated for their inter-related businesses. It also show different types of dynamics (logistics/supplier related uncertainty, operations related uncertainty, workforce related uncertainty, machine related uncertainty and demand related uncertainty) in the different stages of supply chain. 


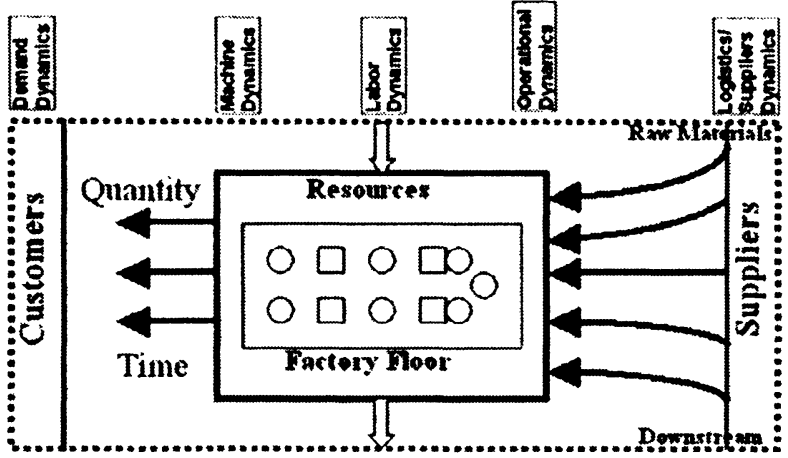

Figure 1. A Typical Supply Chain

Healthcare is gaining more attention from practitioners as well as manufacturing sectors. Due to cheap labor, less union problem and some other factors, companies are shifting their facilities overseas from United States. Global logistics systems are becoming more challenging due to outsourcing. A global logistics network for medical equipment manufacturing system is shown in Figure 2. The managing such logistics systems are needed to be considered for best customer services due to lot of dynamics are involved in the systems. Forrester illustrates the effect in a series of case studies and points out that it is a consequence of industrial dynamics or time varying behaviors of industrial organizations [1]. Within the area, industrial dynamics research has concentrated on logistics information and delay in the supply chain system [2-4]. Industrial dynamics research has concentrated on logistics information and delay in the supply chain system [5]. The decisions for supply chain management are mainly of two categories such as strategic (external) and operational (internal). Strategic decisions are made typically over a long time horizon which is closely linked to the corporate strategy and guides supply chain policies from a design perspective. Arntzen et al. [6] provide the most compressive deterministic model for supply chain management to minimize a combination of cost and time elements. Nicholson et al. addressed the issue of managing inventory costs in a healthcare setting [7]. It found, that the recent trend of outsourcing to distribute non-critical medical supplies directly to the hospital departments using them (i.e., the two-echelon network) results not only in inventory cost savings but also does not compromise the quality of care as reflected in service levels.

Spekman et al. [8] develop the concept of supply chain management and argues that only through close collaborative linkages through the entire supply chain, can one fully achieve the benefits of cost reduction and revenue enhancing behaviors. Wilding [9] provides a framework for understanding the generation of uncertainty within supply chains. On the other hand, operational decisions are short term and focused on activities over a day-to-day basis. The effort in these types of decisions is to effectively and efficiently manage the product flow in the internal supply chain. Burnham addresses the systematic logistics improvement principles where Global Logistics Systems (GLS) has been addressed strategic and tactical issues for timely and accurate delivery, availability, and lowest total cost [10]. Stock explores and 
develops the concept of enterprise logistics as a tool for integrating the logistics activities both within and between the strategically aligned organizations of the extended enterprise [11]. It is indicated that enterprise logistics is a necessary tool for the coordination of supply chain operations that are geographically dispersed around the world. However, for a pure network structure, a high level of enterprise logistics integration alone does not guarantee improved organizational performance. The paper ends with a discussion of managerial implications and directions for future research.

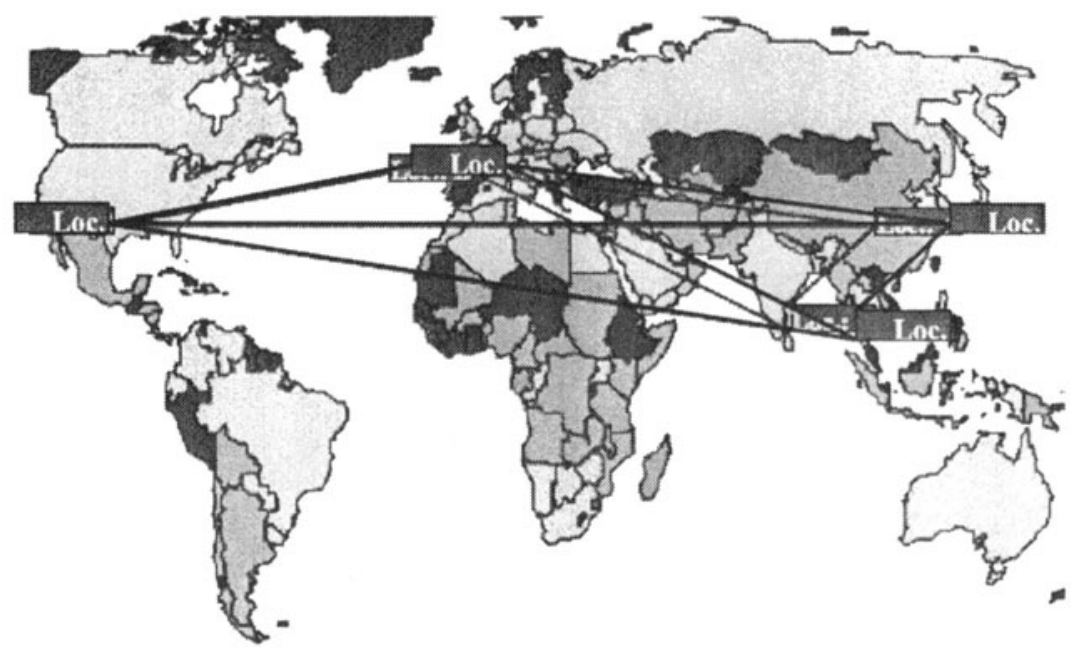

Figure 2. Global Logistics Network of Medical Equipment Manufacturing

With global competition intensifying and companies battling to keep market share, it is imperative that they carefully manage costs while maintaining service levels. Many companies are considering outsourcing transportation and distribution functions as a way to reduce costs. Companies need ways to measure service. Well-defined metrics can help a company measure costs and service and analyze tradeoffs between the two. Byers develops a list of potential metrics for distribution and transportation operations, and constructs a conceptual framework [12]. Pontrandolfo et al. focuses on the issues of coordination in the area of logistics (i.e. supply, manufacturing and distribution phases) of global manufacturing networks and propose a framework that systematically addresses the global manufacturing planning (GMP) problem by identifying and classifying the variables involved therein [13]. In recent years, researchers and practitioners alike have devoted a great deal of attention to supply chain management (SCM). The main focus of SCM is the need to integrate operations along the supply chain as part of an overall logistic support function. At the same time, the need for globalization requires that the solution of SCM problems be performed in an international context as part of what we refer to as Global Supply Chain Management (GSCM). An approach to study GSCM problems using an artificial intelligence framework is proposed and called reinforcement learning (RL) [14]. The 
RL framework allows the management of global supply chains under an integration perspective.

\subsection{Supply Chain Decision System}

The main goal of supply chain management is to integrate and optimize the business and operational functions of an enterprise. Stewart [15] gives the first crossindustry framework for evaluating and improving enterprise-wide supply-chain performance and management, which is known as the supply-chain operations reference (SCOR) model. The SCOR methodology developed by the supply chain council addresses and benchmarks supply chains. These entities receive and process information from both the supply and demand management systems so as to derive the optimized enterprise supply chain infrastructure. As planning for the inbound, manufacturing and outbound functions are clustered together in this model, it is deemed necessary to have a logical separation between inbound, manufacturing and outbound. This is to allow further examinations of the activities that have occurred within each of these functions. In upstream inbound planning, manufacturers have to co-ordinate the inbound materials. Down stream manufacturers have to plan the outbound distribution strategy. Both the streams have unique physical distribution network topologies. These planning strategies and distribution topologies are documented and observed by small to medium size enterprises. It involves balancing the company's needs on both the supply side and the demand side and in harmonizing this with all the actors in the supply chain to achieve demand pipeline leadership, which is shown in Figure 3.

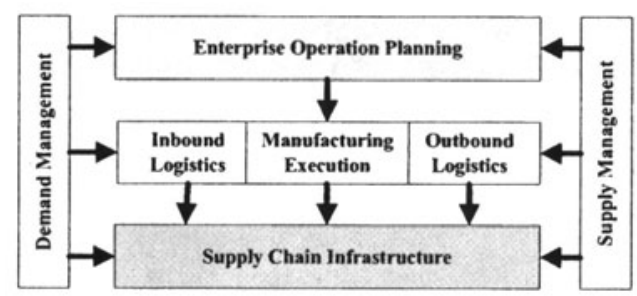

Figure 3. SCM Decision System

\subsection{Enterprise Operation Planning (EOP)}

EOP function resides within the manufacturing decision system function. The primary utilization of EOP is to provide global visibility of forecasts, inventory and production by consolidating data from multi-sites and databases. It has a centralized planning function to support global supply chain management and the relationships between demand and supply. This information is then translated to allocation of production demands to various sites. The EOP function links the high-level manufacturing enterprise business planning with medium to short-term planning and execution activities. Tactically, EOP optimizes target inventory and production levels by identifying variances between planned and actual performance. It also develops 
site and production line schedules in a typical high-mixed, high-volume manufacturing company.

In one-way or another, EOP enables supply chain integration to meet the customers' demands across the entire virtual enterprise which includes the immediate company, all its suppliers and customers. This is different from the traditional integration focus, which creates imbalance between the demand side (i.e. the customers, corporate entities, sales and marketing) and supply side (i.e. design, logistics, manufacturing and supplier). Although many companies that used the traditional integration methodology are able to integrate one side (supply or demand side) or the other, however, there has been little interaction between the two.

The mapping of a real life problem involves a wide range of knowledge such as production knowledge and mathematical knowledge, which actually make it very difficult to be used in supply chain management. That is to say, the planner should decide the quantity of each combination to meet the demand, concerning the full utilization of material at the same time. The product combination scenario is shown in Figure 4. Of course, it is very difficult for the planner to solve this large problem as a mathematical model efficiently and correctly without the help of computer and an effective algorithm of optimization. So how to model such large-scale problem more easily and more accurately is the attention of the research. As genetic algorithms have proved their contribution to complex problems, the system may be solved easily and more accurately.

\section{MATHEMATICAL FORMULATION}

The mathematical formulation has been described in respect to a real problem scenario. The global logistics problems are considered in terms of logistics cost minimization. It can provide proper information about production control to improve customer service. This scenario is basically for the medical equipment supply chains. The detailed configuration and design structure of the logistics network is shown figure. In order to identify the various factors that influence the overall logistics cost, a cause and effect diagram will be developed. There are many possible causes that have a direct influence on the overall logistics cost such as capacity, lead time, inventory cost, manufacturing cost, forecasting and shipping cost. Based on the determination of important factors, the following mathematical formulation has been developed to minimize the cost. 
116 Sk Ahad Ali, Hamid Seifoddini and Jay Lee

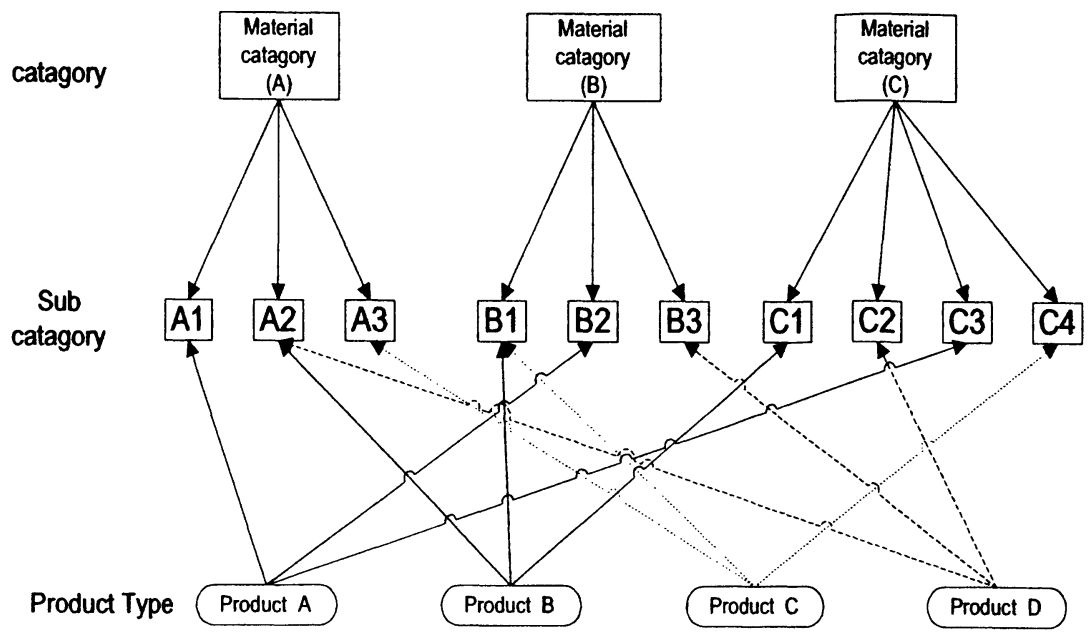

Figure 4. Product Combination Scenario

Product types: $\mathrm{P} 1, \mathrm{P} 2, \ldots \ldots \ldots, \mathrm{Pn}$, where $\mathrm{n}$ is the type of products

Demand quantity, D1, D2,....., Dn, in respect of product type P1, P2,......, Pn

Locations: $\mathrm{L} 1, \mathrm{~L} 2, \ldots \ldots, \mathrm{Lm}$, where $\mathrm{m}$ is the number of locations

Manufacturing cost: $\mathrm{MC1}, \mathrm{MC} 2, \ldots \ldots ., \mathrm{MCm}$

Shipping cost (finished products): FC11, FC12, ......, FCmm

Shipping cost (sub assembles): SC11, SC12,....., SCmm

Inventory cost: $\mathrm{IC} 1, \mathrm{IC} 2, \ldots \ldots \ldots, \mathrm{ICm}$

Shipping plan: SP11, SP12, ...., SPmm

Total shipping cost $=[\mathrm{D} 1, \mathrm{D} 2, \ldots \ldots \ldots . ., \mathrm{Dn}] *[\mathrm{SC} 11, \mathrm{SC} 12, \ldots \ldots ., \mathrm{SCmm}]+[\mathrm{D} 1$, $\mathrm{D} 2, \ldots \ldots \ldots \ldots, \mathrm{Dn}] *[\mathrm{MC} 1, \mathrm{MC} 2, \ldots \ldots ., \mathrm{MCm}]+[\mathrm{D} 1, \mathrm{D} 2, \ldots \ldots \ldots \ldots, \mathrm{Dn}] *[\mathrm{IC} 1$,

$\mathrm{IC} 2, \ldots \ldots \ldots . ., \mathrm{ICm}]+[\mathrm{SP} 11, \mathrm{SP} 12, \ldots, \mathrm{SPmm}] *[\mathrm{FC} 11, \mathrm{FC} 12, \ldots \ldots \ldots, \mathrm{FCmm}]$

\subsection{Constraints}

The constraints of the global logistics systems are following:

\section{Capacity Constraints}

Each product needs to be checked with the customer order against available capacity of the real shop floor. This capacity check will give the customer committed demand that will assist to provide optimal logistics scenario for each product. 


$$
\begin{aligned}
& D_{1} \leq C_{1} \\
& D_{2} \leq C_{2} \\
& \cdots \cdots \cdots \\
& D_{n} \leq C_{n}
\end{aligned}
$$

Where $C_{n}(k=1,2, \cdots \cdots \cdots, N)$ is the capacity of the $n^{\text {th }}$ product that depends upon real time shop floor level. This real time capacity gives more realistic logistic strategy.

\section{Sub Assembles Constraints}

Sub Assembles constraints state that the total number of type components consumed in every moving window cannot exceed the maximum number of components needed, i.e.,

$$
\sum_{i=1}^{n} S A_{i} \leq \sum_{i=1}^{n} C A_{i}
$$

SA - Sub assembles, CA - Capacity assembles

\section{Demand Constraints}

The commit demand must be equal to or less than the product demands of the customer i.e. commit demand cannot exceed the customer demand that can be expressed as:

$$
\sum_{\substack{i=1 \\ j=1}}^{m, m} S P_{i j} \leq \sum_{\substack{i=1 \\ j=1}}^{m, m} D P_{i j}
$$

Where, $\mathrm{SY}_{\mathrm{ij}}$ and $\mathrm{DP}_{\mathrm{ij}}$ are the shipping plan and demand plan respectively.

\section{Logistics Fuzzy Rules as Constraints}

The suppliers' behaviors are needed to be identified to consider the supplier dynamics. The supplier's behavior is characterized based on timely delivery, quality and flexibility. The IF-THEN rule based fuzzy rules are used for the supplier's behavior.

Rule 1: IF $x_{1}$ is $A_{1}{ }^{1}$ and (or) ... and (or) $x_{n}$ is $A_{n}{ }^{1}$

THEN $y_{1}$ is $B_{1}{ }^{1}$ and (or) ... and (or) $y_{m}$ is $B_{m}{ }^{p}$

Rule $k$ : IF $x_{1}$ is $A_{1}{ }^{k}$ and (or) ... and (or) $x_{n}$ is $\dot{A}_{n}{ }^{k}$

Where,

THEN $y_{1}$ is $B_{1}{ }^{p}$ and (or) ... and (or) $y_{m}$ is $B_{m}{ }^{q}$

$x_{1 \ldots n}$ independent fuzzy variables (antecedent)

$y_{1 \ldots m}$ independent fuzzy variables (consequent)

$A_{i}^{1 \ldots p}$ fuzzy sets corresponding to $x_{i}$

$A_{j}^{1 \cdots q}$ fuzzy sets corresponding to $y_{j}$ 


\subsection{Objective Function}

The total logistics cost is considered as objective function and the cost should be minimized.

$$
T C=\sum_{\substack{i=1 \\ i=1}}^{n, m}\left(\left[D_{i}\right] \times\left[\left\{M C_{j}\right\},\left\{S C_{j j}\right\},\left\{F C_{i j}\right\},\left\{I C_{j}\right\}\right]\right)
$$

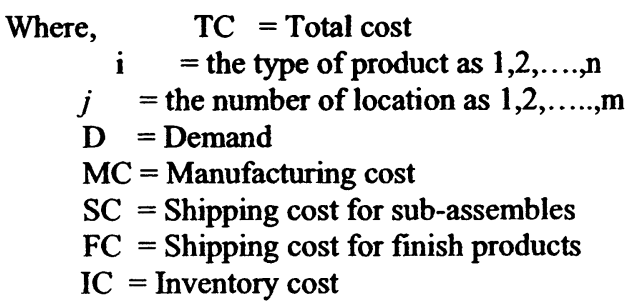

\section{CASE STUDY: MEDICAL EQUIPMENT MANUFACTURING SYSTEM}

In order to achieve high economies of scale and shorten the logistics and supply chain lead-times, medical equipment manufacturing system has its manufacturing operations set up in various parts of the globe. Whatever be the location of these facilities, the company has identified "continuous improvement" as the driving factor for its consistent growth year after year. The company has embraced Internet as a key tool in reducing cost. Whether it is improving its responsiveness to the customers in order to offer better equipment diagnostics or sharing of information, it has exploited the benefits of internet to the maximum and has improved its bottom line.

This research provides an effort to optimize the logistics performance of one of medical equipment manufacturing system's key products, X-Ray Scanner. The product has three models that are made in three different locations. Company does not manufacture all the parts needed for assembly at one location. This means that some of the parts are procured from other locations and these are then assembled at a particular facility, tested for quality and sent to the customer i.e. the hospital. When an order is received for a specific model, the company has to identify the best location for its assembly and manufacture of an X-Ray model to maintain high customer service level and at the same time minimize the overall logistics cost. The following objectives are identified to solve logistics problems:

- To build an LP optimization model using Arena OptQuest for minimizing the overall logistics cost

- Identify the uncertainty of factors that affect the overall logistics cost using Design of Experiments

- Propose best practices in the industry for global logistics

\subsection{Problem Formulation}


Due to the constraints on the level of data that was available, the project focused on formulation as an important step. It will generate an optimal solution, however the company can use the factors considered in the formulation steps to improve this optimal solution and further minimize its logistics cost in the future.

The product X-Ray Scanner has the following components/parts:

- Gantry 1 (premium)

- Gantry 2 (mid tier)

- Gantry 3 (3 $^{\text {rd }}$ tier $)$
- Console 1

- Console 2

- Console 3
- Table

- Accessories

An X-Ray Scanner consists of a gantry, console, table and accessories. There are three different models that can be assembled from this product mix. Tables and accessories are the same for any kind of model with variations in gantries and consoles. The locations in which these parts are made are given in Table 1 .

Table 1. Manufacturing Locations for Various Parts

\begin{tabular}{|l|l|l|l|}
\hline Location A & Location B & Location C & Location D \\
\hline Gantry 2 & Gantry 1 & Gantry 1 & Accessories \\
\hline Gantry 3 & Gantry 2 & Console 1 & \\
\hline Console 2 & Console 1 & & \\
\hline Console 3 & Console 2 & & \\
\hline Table & & & \\
\hline
\end{tabular}

It can be seen from the table that a gantry and console of similar types are made in the same manufacturing location. Hence, for purpose of simplicity we grouped each gantry and console type and call them under a generic name of product type. Thus, Location A makes product type 2 and 3. Location B manufactures product type 1 and 2 and Location 3 manufactures only product type 1 . Tables are manufactured only in Location A. Thus assembly of X-Ray Scanners is two locations. Tables are supplied from Location A. Location D makes only accessories and supply it to all three plants that manufacture and assemble the X-Ray scanners. Location and customers maps are shown in Figure 5.

In order to identify the various factors that influence the overall logistics cost, a cause and effect diagram is built. As seen from Figure 6, the six possible causes are identified that have a direct influence on the overall logistics cost. They are capacity, lead time, inventory cost, manufacturing cost, forecast and shipping cost. Based on the determination of important factors and the availability of data, the model has been developed. 
120 Sk Ahad Ali, Hamid Seifoddini and Jay Lee

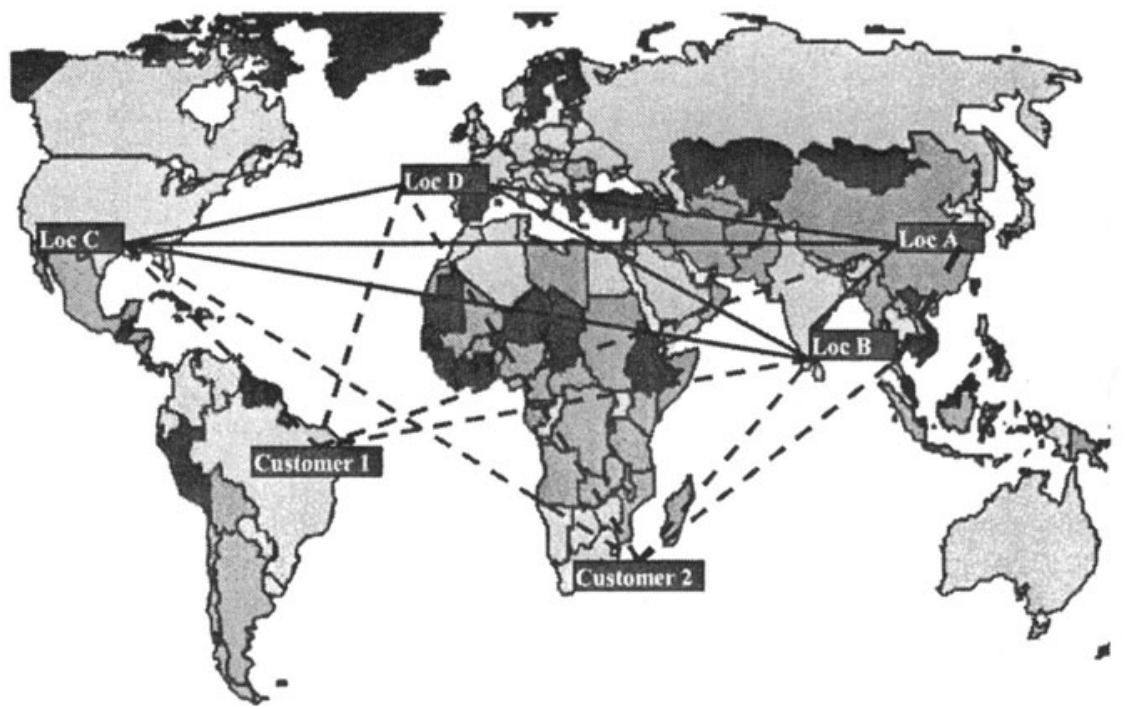

Figure 5. Global Logistics Network with Customers

\subsection{Optimal Algorithm}

The algorithm is developed for the logistics and supply chain networks of their distribution center and plants to optimize their logistics networks using LINDO. The objective is to minimize total logistics cost for a specific product type, given the capacity constraints in the specific plants. The demand, all cost related on shipping, manufacturing, inventory and shipping plan are in Table $2-7$.

Table 2. Demand for X Ray Scanners

\begin{tabular}{|c|c|c|c|c|}
\hline & Location A & Location B & Location C & Location D \\
\hline P1 & 250 & 100 & 250 & 329 \\
\hline P2 & 0 & 0 & 0 & 0 \\
\hline P3 & 0 & 0 & 0 & 0 \\
\hline
\end{tabular}




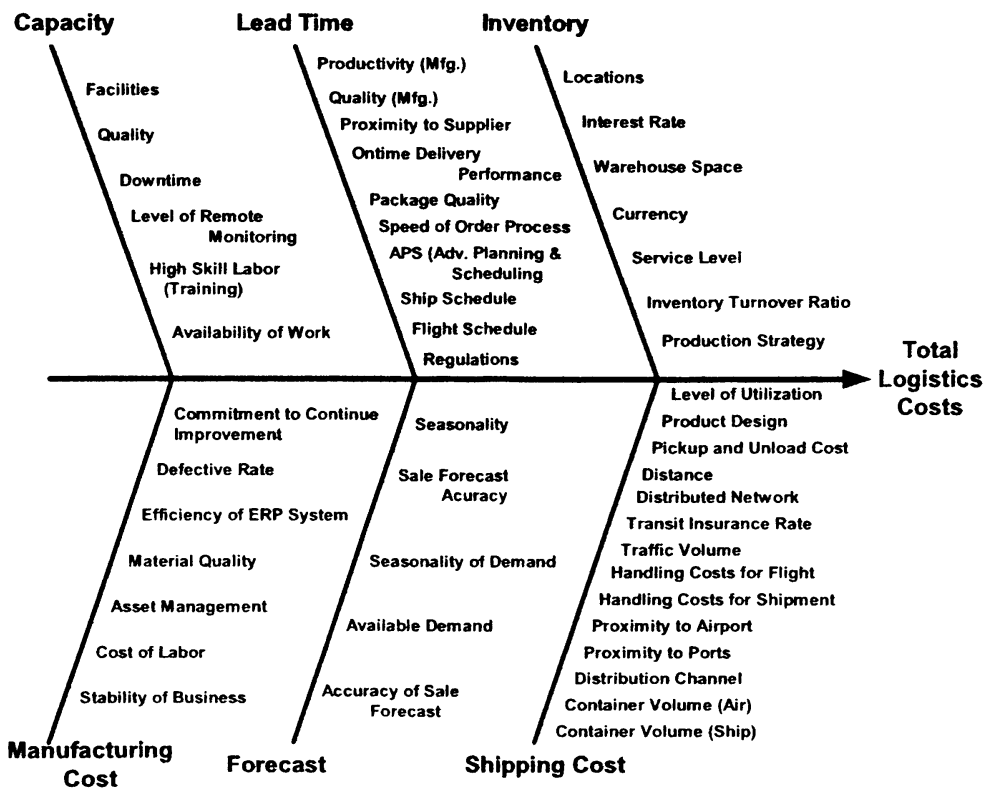

Figure 6. Logistics Cost Factor Analysis

Table 3. Transportation Cost (Finished Products)

\begin{tabular}{|l|c|c|c|c|}
\hline & Location A & Location B & Location C & Location D \\
\hline Location A & 50 & 500 & 575 & 625 \\
\hline Location B & 500 & 50 & 600 & 700 \\
\hline Location C & 575 & 585 & 45 & 250 \\
\hline Location D & 625 & 700 & 350 & 50 \\
\hline
\end{tabular}

Table 4. Shipping Plan

\begin{tabular}{|c|c|c|c|c|c|c|}
\hline & \multicolumn{5}{|c|}{ Market } & \multirow[b]{2}{*}{ Capacity } \\
\hline & Loc. A & Loc. B & Loc. 9 & Loc. D & Total Production & \\
\hline Location A & 0 & 0 & 0 & & & \\
\hline Location B & 250 & 100 & 54 & 0 & 404 & 4750 \\
\hline Location $\mathrm{D}$ & 0 & 0 & 196 & 329 & 525 & 525 \\
\hline Total & 250 & 100 & 250 & 329 & 929 & \\
\hline
\end{tabular}

Table 5. Transportation Cost (Sub-assembles)

\begin{tabular}{|l|l|l|l|l|}
\hline & Loc. A & Loc. B & Loc. C & Loc. D \\
\hline Loc. A & & 300 & 250 & 275 \\
\hline Loc. C & 225 & 275 & & 125 \\
\hline
\end{tabular}


122 Sk Ahad Ali, Hamid Seifoddini and Jay Lee

Table 6. Manufacturing Cost

\begin{tabular}{|l|l|l|l|l|}
\hline & Loc. A & Loc. B & Loc. C & Loc. D \\
\hline Accessories & & & 110 & \\
\hline Tables & 200 & & & \\
\hline P1 & & 100 & & 225 \\
\hline P2 & & & & \\
\hline P3 & & & & \\
\hline
\end{tabular}

Table 7. Inventory Cost

\begin{tabular}{|l|l|l|l|l|}
\hline & Loc. A & Loc. B & Loc. C & Loc. D \\
\hline Accessories & & & 25 & \\
\hline Tables & 30 & & & \\
\hline P1 & & 50 & & 45 \\
\hline P2 & & & & \\
\hline P3 & & & & \\
\hline
\end{tabular}

\subsection{Effect of Factor Uncertainty}

We used a DOE (design of experiment) model to identify the effect of each factor on the response variable, i.e. the total logistics cost. Five-key factors (interest rate, traffic volume, handling cost, distribution cost and labor cost) influencing the overall logistics cost are identified. We assigned weights to each factors and carried out $1 / 2$ factorial design.

Table 8. Design Matrix for DOE and Results

\begin{tabular}{|r|r|r|r|r|r|r|r|r|}
\hline \multicolumn{1}{c}{$\begin{array}{l}\text { Interest } \\
\text { Rate }\end{array}$} & $\begin{array}{c}\text { Traffic } \\
\text { Volume }\end{array}$ & $\begin{array}{c}\text { Handling } \\
\text { Cost }\end{array}$ & $\begin{array}{c}\text { Distr. } \\
\text { Cost }\end{array}$ & $\begin{array}{c}\text { Labor } \\
\text { Cost }\end{array}$ & $\begin{array}{c}\text { Inventory } \\
\text { Cost }\end{array}$ & $\begin{array}{c}\text { Mfg. } \\
\text { Cost }\end{array}$ & $\begin{array}{c}\text { Tran. } \\
\text { Cost }\end{array}$ & $\begin{array}{l}\text { Optimal } \\
\text { Rate }\end{array}$ \\
\hline 1 & 1 & -1 & -1 & 1 & 1 & 1.00000 & 0.96 & 632943 \\
1 & 1 & 1 & 1 & 1 & 1 & 1.00000 & 1.00 & 648465 \\
-1 & -1 & 1 & -1 & -1 & 0.94 & 0.98000 & 0.96 & 625997 \\
1 & -1 & -1 & -1 & -1 & 1 & 0.97330 & 0.96 & 627149 \\
-1 & -1 & 1 & 1 & 1 & 0.94 & 0.99333 & 1.00 & 644414 \\
-1 & -1 & -1 & 1 & -1 & 0.94 & 0.98666 & 0.96 & 627444 \\
-1 & 1 & 1 & 1 & -1 & 0.94 & 1.00000 & 0.96 & 630339 \\
-1 & 1 & -1 & 1 & 1 & 0.94 & 0.99333 & 1.00 & 644414 \\
1 & -1 & 1 & 1 & -1 & 1.00 & 0.99333 & 0.94 & 623735 \\
-1 & 1 & 1 & -1 & 1 & 0.94 & 0.98666 & 1.00 & 642966 \\
-1 & 1 & -1 & -1 & -1 & 0.94 & 0.98000 & 0.94 & 618238 \\
1 & 1 & 1 & -1 & -1 & 1 & 0.98666 & 0.94 & 622287 \\
1 & -1 & 1 & -1 & 1 & 1 & 0.98000 & 1.00 & 644125 \\
1 & 1 & -1 & 1 & -1 & 1 & 0.99333 & 0.94 & 623735 \\
1 & -1 & -1 & 1 & 1 & 1 & 0.98666 & 1.00 & 645570 \\
-1 & -1 & -1 & -1 & 1 & 0.94 & 0.97330 & 1.00 & 640073 \\
\hline
\end{tabular}




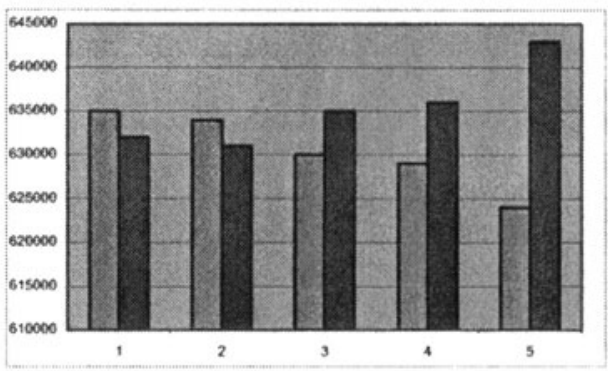

1- Interest rate

2-Traffic volume

3-Handling cost

4-Distribution cost

5-Labor cost

Figure 7. Effect of the Factors Considered

The results of the DOE are given in Figure 7, which indicates that the effect of labor cost, distribution cost and the handling cost have a significant impact on the overall logistics cost. From the results, we observe that labor cost has the greatest impact on the optimal cost. In the future, this factor needs to be taken care of.

\section{CONCLUSIONS}

The global logistic network has been pointed out to show the impact of the different cost factors considered for medical equipment manufacturing systems. The formulation of the logistics network has been shown in details and a case sudsy has been done on medical system and shows the optimal production and cost scenario. The proposed methodology can be used to improve the any logistics systems specifically in medical equipment manufacturing systems.

\section{REFERENCES}

1. J.W. Forrester, Industrial Dynamics (MIT Press: Boston, MA 1961).

2. J.L. Burbidge, The New Approach of Production, Production Engineer. Volume 40, pp.769-784, (1961).

3. D.R. Towill, Supply Chain Dynamics, Computer Integrated Manufacturing. Volume 4, pp.197-208, (1991).

4. D.R. Towill, Supply Chain Dynamics-The Change Engineering Challenge of the Mid 1990s, in Proceedings of the Institution of Mechanical Engineers Volume 206 (1992), pp.233-245.

5. D.R. Towill, Industrial Dynamics Modelling of Supply Chains, International Journal of Physical Distribution and Logistics Management. Volume 26, Number 2, pp.23-42, (1996).

6. B.C. Arntzen, G.G. Brown, T.P. Harrison, and L.L. Trafton, Global Supply Chain Management at Digital Equipment Corporation, Interfaces. Volume 25, Number 1, pp.6993, (1995).

7. L. Nicholson, A.J. Vakharia, and S.S. Erenguc, Outsourcing Inventory Management Decisions in Healthcare: Models and Application, European Journal of Operations Research. Volume 154, Number 1, pp.271-290, (2004). 
8. R.E. Spekman, J.W. Kamauff, and N. Myhr, An Empirical Investigation into Supply Chain Management: A Perspective on Partnerships, Supply Chain Management. Volume 3, Number 2, pp.53-67, (1998).

9. R. Wilding, The Supply Chain Complexity Triangle: Uncertainty Generation in the Supply Chain, International Journal of Physical Distribution and Logistics Management. Volume 28, Number 8, pp.599-616, (1998).

10. J.M. Burnham, Systematic Logistics Improvement: Integrating Principles and Practices, in Proceedings of the APICS 35th International Conference and Exhibition (1992), pp.500-510.

11. G.N. Stock, N.P. Greis, and J.D. Kasarda, Enterprise Logistics and Supply Chain Structure: The Role of Fit, Journal of Operations Management. Volume 18, Number 5, pp.531-547, (2000).

12. J.E. Byers, T.L. Landers, and S. Anderson, Framework for Logistics System Metrics, in Proc. of the 1996 ASME International Mechanical Engineering Congress and Exposition, Volume 4 (Atlanta, 1996), pp.773-781.

13. P. Pontrandolfo and O.G. Okogbaa, Global Manufacturing: A Review and a Framework for Planning in a Global Corporation, International Journal of Production Research. Volume 37, Number 1, pp.1-19, (1999).

14. P. Pontrandolfo, A. Gosavi, O.G. Okogbaa, and T.K. Das, Global Supply Chain Management: A Reinforcement Learning Approach, International Journal of Production Research. Volume 40, Number 6, pp.1299-1317, (2002).

15. G. Stewart, Supply Chain Operations Reference Model (SCOR): The First Cross-Industry Framework for Integrated Supply Chain Management, Logistics Information Management. Volume 10, Number 2, pp.62-67, (1997). 